\title{
Planejamento Estratégico Pessoal
}

\author{
Rolando Juan Soliz Estrada ${ }^{1}$ \\ Luis Moretto Neto ${ }^{2}$ \\ Eziane Samara Augustin ${ }^{3}$
}

\section{Resumo}

Conciliar as habilidades pessoais com as exigências de um mercado globalizado e competitivo tornou-se um pré-requisito para os profissionais que aspiram sucesso em suas carreiras. A busca por realização pessoal tem incentivado as pessoas a procurarem ferramentas que desenvolvam seus talentos e equilibrem seus esforços, a fim de conquistarem uma vida melhor, mais feliz e saudável. Como alternativa, o planejamento, que até então se detinha a uma ferramenta organizacional, hoje vem sendo igualmente utilizado pelos indivíduos que desejam o sucesso pessoal. Dessa forma, o presente trabalho tem como objetivo desenvolver um modelo de Planejamento Estratégico Pessoal que contemple as diversas áreas de atuação e desempenho humano. O modelo proposto neste trabalho está dividido em: Planejamento Individual, Planejamento Profissional, Planejamento Familiar, Planejamento de Negócios Pessoais e Planejamento da Participação Política, Social e Religioso/Espiritual e seus respectivos campos. Foi utilizada a pesquisa exploratória, de natureza qualitativa, por meio da utilização de fontes primárias e secundárias de dados, a fim de analisar e validar o modelo. A partir dos resultados obtidos pelo modelo, é possível considerar sua importância para futuras pesquisas, uma vez que as áreas estudadas poderão ser aprofundadas em trabalhosposteriores.

Palavras-chave: Planejamento Estratégico Pessoal. Planejamento Pessoal. Planejamento de Carreira.

\footnotetext{
${ }^{1}$ Pós-Doutor em Administração pela Universidade de São Paulo - USP. Doutor em Engenharia de Produção pela Universidade Federal de Santa Catarina - UFSC. Professor do Programa de Pós-Graduação em Engenharia de Produção da Universidade Federal de Santa Maria - UFSM. End: Departamento de Engenharia de Produção e Sistemas, Centro de Tecnologia, Universidade Federal de Santa Maria, Av. Roraima n 1000 , Cidade Universitária, Camobi, Santa Maria - RS. CEP: 97105-900 - Brasil. E-mail: rolando@smail.ufsm.br.

${ }^{2}$ Doutor em Engenharia de Produção e mestrado em Geografia -Desenvolvimento Regional e Urbano pela Universidade Federal de Santa Catarina -UFSC. Atualmente é Professor Associado III da Universidade Federal de Santa Catarina -UFSC. End.: Universidade Federal de Santa Catarina, Campus Universitário, s/n, Trindade-Florianopolis, SC. CEP: 88040-900 -Brasil. E-mail: moretto@cse.ufsc.br

${ }^{2}$ Mestre em Engenharia de Produção pela Universidade Federal de Santa Maria - UFSM. End: Programa de Pós-Graduação em Engenharia de Produção, Centro de Tecnologia, Universidade Federal de Santa Maria-UFSM. End.: Av. Roraima n ${ }^{\circ}$ 1000, Cidade Universitária, Camobi, Santa Maria-RS. CEP: 97105-900 - Brasil. E-mail: ezyaugustin@yahoo.com.br.

Artigo recebido em: 27/12/2010. Aceito em: 03/03/2011. Membro do Corpo Editorial Científico responsável pelo processo editorial: Martinho Isnard Ribeiro de Almeida.
} Esta obra está sob uma Licença Creative Commons Atribuição-Uso. 


\section{Introdução}

O ambiente empresarial está em constante mudança e cada vez mais competitivo. A natureza complexa e imprevisível desse cenário vem obrigando as empresas a repensarem suas ferramentas administrativas e a atuarem de forma flexível, em face dessas mudanças. Entre tais mudanças, o planejamento estratégico tem mostrado ser uma eficaz alternativa para o crescimento das empresas, visando alavancar o potencial da empresa, por meio da análise de fatores internos e externos que atuam sobre a organização. Stoner e Freeman (1995) enfatizam que o planejamento estratégico é um processo de decisões inter-relacionadas e interdependentes, tendo como aspecto básico a determinação dos objetivos e dos meios para alcançá-los.

Com a utilização dessa ferramenta, pretende-se, não adivinhar o futuro, mas construí-lo, evitando, ao máximo, as surpresas, racionalizando o processo de tomada de decisão e garantindo o sucesso da empresa em seu ambiente (SAMPAIO, 2002).

O planejamento estratégico caracteriza-se por ser um processo dinâmico e flexível, que permite incorporar as mudanças do ambiente. Uma vez que a demanda por constantes inovações e por aperfeiçoamento, exigida pelo mercado, não se restringe apenas ao cerne das organizações, mas está presente na vida diária do indivíduo, antecipar-se a essas mudanças torna-se uma necessidade, tanto empresarial, na busca por diferenciais competitivos, quanto pessoal, na procura por autorrealização. Em função dessa necessidade, o Planejamento Estratégico Pessoal, no intuito de determinar as principais diretrizes que auxiliarão o indivíduo a atingir a realização pessoal, tornou-se objeto de estudo de muitos pesquisadores.

O planejamento estratégico pessoal faz o indivíduo refletir e levantar questionamentos a respeito de seu modo de vida, princípios, fatores de sucesso e fracasso e de suas competências, que poderão dar origem a uma vantagem competitiva. Esse planejamento inclui a ideia de um futuro desejado, servindo de motivador para a pessoa persistir na trilha traçada (SHIBATA, 2007). Pires (2005) complementa afirmando ser o planejamento pessoal a chave para a autorrealização e para o sucesso, além da motivação e do equilíbrio entre a vida pessoal e a profissional.

O principal objetivo desta pesquisa consiste no desenvolvimento de uma ferramenta que contemple todos os aspectos da vida pessoal, sendo, para tanto, necessária uma análise dos modelos de planejamento pessoal 
existentes e a validação do modelo de Planejamento Estratégico Pessoal proposto.

O modelo de planejamento desenvolvido visa atender às expectativas do indivíduo que almeja sua autorrealização e que colabora com a ciência, à medida que suas áreas podem ser aprofundadas em estudos posteriores.

\section{Metodologia}

O presente trabalho trata-se de uma pesquisa exploratória, que analisa os modelos de planejamento pessoal existentes, e, a partir deles, desenvolve um Modelo de Planejamento Estratégico Pessoal. Tal classificação justificase uma vez que, segundo Gil (2002, p. 41), o objetivo principal dos estudos exploratórios é "[...] o aprimoramento de idéias ou a descoberta de intuições. Seu planejamento é, portanto, bastante flexível, de modo que possibilite a consideração dos mais variados aspectos relativos ao fato estudado [...]", sendo, portanto, o mais adequado para tal estudo, e o que atende a finalidade de análise e de proposição científica sem, no entanto, ter a pretensão de esgotar o tema pesquisado.

Quanto à abordagem do problema, o trabalho utilizou a pesquisa qualitativa, que, de acordo com Diehl e Tatim (2004), tem o objetivo de compreender e classificar os processos dinâmicos vivenciados por grupos sociais, podendo descrever a complexidade de determinado problema e a interação de algumas variáveis.

Os dados foram coletados em fontes primárias e secundárias. As fontes primárias foram obtidas, de acordo com a classificação proposta por Gil (2002), por meio de: livros de leitura corrente (obras de divulgação), livros de referência informativa (dicionários), livros de referência remissiva (monografias, dissertações e teses), publicações periódicas (jornais e revistas) e impressos diversos.

As fontes secundárias provêm de entrevistas semiestruturadas, cuja ordem e redação das perguntas permaneceram inalteradas para todos os entrevistados. As entrevistas foram aplicadas aos participantes da primeira e da segunda turma do curso de Planejamento Estratégico Pessoal. Essa amostra foi escolhida, segundo Gil (2002), por acessibilidade (ou por conveniência) e constitui o mais flexível de todos os tipos de amostragem, pois é destituída de qualquer rigor estatístico. Nesse tipo de amostragem, o pesquisador sele- 
ciona os elementos a que tem acesso, admitindo que eles possam, de alguma forma, representar o universo. A amostra por acessibilidade é usada em estudos exploratórios, em que não é requerido elevado nível de precisão. A amostra foi baseada em entrevista semiestruturada, realizada com as nove pessoas que participaram.

Depois de coletar os dados, eles foram analisados e interpretados, permitindo extrair as informações necessárias para a validação do Modelo de Planejamento Estratégico pessoal desenvolvido. Uma vez que, de acordo com Gil (1999), a análise tem como objetivo organizar e sumariar os dados, de forma tal que possibilitem o fornecimento de resposta ao problema proposto para investigação, essa análise foi fundamental para a conclusão e para as recomendações da pesquisa.

\section{Planejamento Estratégico (PE)}

A aparente falta de sintonia entre a quantidade de produtos ofertados, em relação à capacidade de absorção desses produtos pelo mercado consumidor, tornou imprescindível a análise ambiental por parte das empresas. A necessidade de um bom relacionamento com o ambiente externo ficou mais evidente a partir da década de 1960, a partir do momento em que as organizações passam a ser consideradas sistemas abertos e interligados com o meio.

Diante da percepção de tais interações com o meio, uma série de transformações e reestruturações ocorreu nas empresas, sobretudo, no que tange à estruturação hierárquica, custos, qualificação dos profissionais, dentre outros fatores. Nesse contexto de constantes alterações ambientais e aumento de competitividade, surge então o planejamento estratégico, como resultado evolutivo, proveniente das mudanças no sistema de gestão das organizações.

A respeito disso, Brondani (1999) alega que a dinâmica do meio ambiente, a geração de flexibilidade, a interação da empresa com seus meios, interno e externo, e a revitalização do espírito organizacional são apenas algumas das razões que tornam o planejamento estratégico uma eficaz ferramenta de gestão no atual mercado globalizado.

Ansoff (1981, p. 15) conceitua o planejamento estratégico como sendo:

[...] a análise racional das oportunidades oferecidas pelo meio, dos pontos fortes e fracos das empresas e da esco- 
lha de um modo de compatibilização (estratégia) entre os dois extremos, compatibilização esta que deveria satisfazer do melhor modo possível aos objetivos da empresa. Uma vez escolhida a estratégia, chegava-se à solução essencial, e a empresa deveria procurar implantá-la.

Segundo Oliveira (2002), através do planejamento estratégico, a empresa espera conhecer e melhor utilizar seus pontos fortes, eliminar ou adequar seus pontos fracos, usufruir as oportunidades existentes, evitar as ameaças externas e obter um efetivo plano de trabalho. Na visão de Cotterman e Wilber (2000), além dessas definições, é importante ressaltar que o planejamento estratégico responde a seis perguntas: (1) onde a empresa está?; (2) onde a empresa quer ir?; (3) como a empresa chegará lá?; (4) quando a empresa deve estar lá?; (5) quem a ajudará a empresa a chegar lá? e (6) como a empresa medirá e avaliará o progresso do plano?

\section{Planejamento Estratégico Pessoal (PEP)}

Assim como no ambiente organizacional, o dia a dia das pessoas está cada vez mais submetido a rápidas mudanças, seja em função da introdução de novas tecnologias e informações, seja pela constante busca de realização pessoal. O planejamento estratégico é uma ferramenta de gestão, que busca preparar a empresa para os desafios futuros por meio da definição da visão e missão, da análise de seu ambiente externo e interno, elaboração das estratégias, sua implementação e controle. Prado (2006) salienta que, da mesma forma como as empresas utilizam essa ferramenta para planejar e obter resultados, a pessoa também pode beneficiar-se desse conhecimento, aplicandoo em sua vida. Planejar a vida significa saber onde se está hoje, onde se quer ir e o que deve ser feito para que se atinja os objetivos esperados.

Conforme Costa (2005), o planejamento estratégico pessoal é um método de gerenciamento de vida, que permite maior organização pessoal, potencialização do tempo e dos recursos pessoais, por meio da mudança de hábitos e de atitudes. Esse método consiste em um processo contínuo, necessitando de metodologia, revisão constante e flexibilidade, para incorporar os ajustes que se tornarem necessários (PORTILLO, 1997).

Planejar não é uma tarefa fácil, porém necessária para que, de forma eficaz, uma pessoa possa atingir suas metas. A principal finalidade do plane- 
jamento estratégico pessoal é fazer com que o indivíduo aprenda a planejar o seu crescimento pessoal e profissional, conciliando os recursos que disponha, com as possibilidades que o mundo lhe ofereça, alcançando, assim, seus objetivos. Essa ferramenta deve ser uma preocupação de todo ser humano que compactue com o ideal de ser feliz, próspero e realizado (NAVARRO, 2006).

Para Morrisey (1992, p. 10)

[...] os benefícios do planejamento incluem: uma visão pessoal para o futuro, uma direção clara para a carreira, a criação de oportunidades, o aumento da segurança, preparação para a aposentadoria, a construção $e$ a manutenção de uma vida equilibrada, balanceada e a oportunidade de envolver outros no bem estar do seu futuro.

Além disso, segundo Dinsmore (2002), para fazer o planejamento pessoal é necessário que o indivíduo pense na vida como um projeto integrado, que envolve o trabalho e a família, suas atividades e vontades, o que já fez e o que ainda deseja realizar.

O planejamento estratégico pessoal proporciona inúmeros benefícios a quem o realiza. Ele deve estar de acordo com as necessidades e os desejos de cada pessoa, sendo dotado de uma visão clara de futuro, com objetivos e planos de ações eficazes na busca por uma vida melhor.

\subsection{Modelos de Planejamento Estratégico Pessoal}

Para a elaboração do Modelo de Planejamento Estratégico Pessoal proposto, primeiramente foram analisados os modelos de Covey (2002), de Souza (2003; 2004), de Seiwert (2004), de Cygler (2005) e de Koshy (2005) que abordam a referida temática, a fim de buscar subsídios para o desenvolvimento de um novo modelo.

\section{I.I Modelo de Covey (2002)}

Covey (2002) propõe um modelo estruturado em três partes e baseado em sete hábitos ( 1 - ser pró-ativo; 2 - começar com o objetivo em mente; 3 - primeiro o mais importante; 4 - pensar em ganha-ganha; 5 - procurar 
primeiro compreender e depois ser compreendido; 6 - criar sinergia; e 7 afinar o instrumento), que abrangem a maioria dos princípios fundamentais da eficácia humana (Princípio 1: Visão pessoal; 2: Liderança pessoal; 3: Gerenciamento pessoal; 4: Liderança interpessoal; 5: Comunicação empática; 6: Cooperação criativa e 7: Autorrenovação equilibrada).

a) A parte um se refere à vitória particular e contempla os hábitos 1, 2 e 3, os quais se baseiam, respectivamente, nos princípios 1,2 , e 3 .

b) A parte dois corresponde à vitória pública e aborda os hábitos 4 , 5 e 6, apoiados pelos princípios 4, 5 e 6.

c) Por fim, a parte três tem como base o hábito 7, amparado pelo princípio 7, e enfatiza a importância de manter as dimensões física, mental, espiritual e social em equilíbrio.

Desse modo, por meio de um novo nível de pensamento que "vem de dentro para fora", em que é necessário mudar primeiro a si mesmo para então mudar sua percepção e seu paradigma, o modelo oferece ferramentas para que a pessoa passe da dependência para a interdependência.

\section{I.2 Modelo de Souza (2003; 2004)}

Souza apresenta a Metodologia da Situação Desejada, que encoraja a pessoa a transferir seu sonho para o papel, e, dali, para a realidade, através do desenvolvimento de estratégias e de ações bem planejadas, para a concretização dos projetos pessoais, profissionais, familiares, empresariais e comunitários, de maneira prática e objetiva. Seu modelo enfatiza tanto o porto (onde a pessoa deseja chegar) quanto a travessia (como chegar lá), uma vez que, para a conquista do sucesso, essas duas variáveis devem ser levadas em consideração.

\subsubsection{Modelo de Seiwert (2004)}

O Modelo do Equilíbrio de Tempo, proposto por Seiwert (2004), é composto por quatro categorias que se encontram em dependência recíproca. Essas categorias contemplam o corpo (saúde, alimentação e descanso), o desempenho no trabalho (carreira, dinheiro e sucesso), os contatos (família e amigos) e o sentido (autorrealização e satisfação). O gerenciamento do tempo busca focar no que é realmente importante, colocando em equilíbrio a 
vida pessoal e a profissional. O autor propõe a utilização da Pirâmide de sucesso em busca da eficácia como meio de realizar o planejamento. A pirâmide é composta por sete passos: 1) desenvolver missão, linha e objetivos de vida; 2) fixar os papéis a desempenhar; 3) definir tarefas básicas estratégicas; 4) formular objetivos; 5) planejar efetivas prioridades semanais; 6) encaminhar eficientemente o trabalho diário; e 7) desenvolver energia, força e autodisciplina.

\section{I.4 Modelo de Cygler (2005)}

Cygler (2005) apresenta, em seu modelo, A fórmula do sucesso e da felicidade, sem estresse, o qual é composto por cinco partes: o tempo; a energia; as tarefas; o indivíduo e seus relacionamentos; $e$ as conquistas nas diversas dimensões da vida (física, material, emocional, intelectual, espiritual e social). Essas áreas devem ser gerenciadas, para que a pessoa se torne mais produtiva, eficiente e equilibrada, estando todas circunscritas a um contexto maior, que engloba o Ser, o Fazer, o Ter e o Viver, já que compreender a relação entre eles é fundamental para viver com sucesso e felicidade, sem estresse. Esse modelo permite que cada área seja trabalhada independentemente da outra, admitindo que a pessoa foque naquela que mais lhe interessar.

\section{I.5 Modelo de Koshy (2005)}

Segundo Koshy (2005), o Planejamento Pessoal auxilia o individuo a determinar quem realmente ele é, onde deseja ir e como desenvolver esse caminho. Para isso, o autor propõe uma autorreflexão, a partir de cinco fatores (personalidade, atitudes, valores, papéis e habilidades). Tais fatores são utilizados como filtros para a criação de metas pessoais e profissionais. Assim, o modelo permite compreender os talentos ou as habilidades do indivíduo, aprender como utilizá-los e traçar uma visão clara da trajetória para o sucesso pessoal e profissional. 


\section{Modelo de Planejamento Estratégico Pessoal Proposto}

Após a análise dos modelos de planejamento estratégico pessoal escolhidos, constatou-se que, a maioria dos modelos estudados continham algumas lacunas.

No modelo proposto por Covey, o autor cita as quatro dimensões que a pessoa deve procurar manter em equilíbrio, porém não se aprofunda nos elementos que os compõem. Souza apresenta um modelo mais completo, determinando as áreas que devem ser trabalhadas pela pessoa, mas também não se aprofunda nos elementos que devem compor cada uma dessas áreas.

Seiwert cita quatro categorias que devem ser mantidas em equilíbrio $e$ lista alguns elementos, que em sua percepção, devem estar vinculadas a essas categorias. No entanto, durante sua obra, não explica o conceito desses elementos. Cygler trabalha com cinco áreas, mas não explica os elementos que devem compor cada uma dessas áreas e, sim, como a pessoa pode alcançar o sucesso e a felicidade por meio do equilíbrio entre essas áreas.

Por fim, Koshy trabalha com duas áreas: a pessoal e a profissional. Apesar delas serem duas, a área pessoal é abrangente e envolve vários elementos. No entanto, ele não explica os conceitos desses elementos e nem como eles podem ser trabalhados. É um modelo amplo, mas que se detém mais no autoconhecimento do que nas áreas que deverão ser trabalhadas.

Dessa forma, o Planejamento Estratégico Pessoal aqui apresentado, consiste em uma ferramenta de gerenciamento pessoal, cujo objetivo é determinar as diretrizes básicas que nortearão o projeto de vida do indivíduo, proporcionando autoconhecimento, organização, administração do tempo e estabelecimento de objetivos pessoais. A elaboração do planejamento fornece uma clara visão de onde o indivíduo encontra-se hoje, onde ele deseja chegar e o que é necessário fazer para alcançar o planejado.

A utilização do modelo visa orientar a pessoa em suas principais áreas de atuação, as quais devem estar em harmonia e equilibradas. Para isso, há cinco planejamentos específicos e suas respectivas divisões: Planejamento Individual, Planejamento Profissional, Planejamento Familiar, Planejamento de Negócios Pessoais e Planejamento da Participação Política, Social e Religioso/Espiritual. 


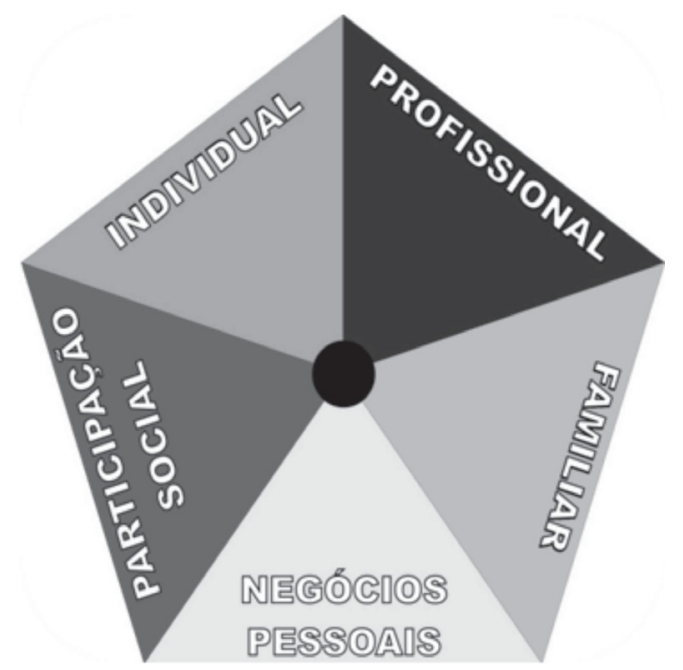

Figura 1: Áreas do Planejamento Estratégico Pessoal proposto

Fonte: Elaborada pelos autores

Cada uma dessas cinco áreas, apresentadas na Figura 1, está dividida em campos, os quais tratam de aspectos relevantes àquele planejamento, conforme mostra a Figura 2. Em função da flexibilidade do modelo, que dá liberdade ao indivíduo para escolher qual planejamento deseja realizar, de acordo com sua necessidade ou preferência, é possível elaborar um plano compatível com as aspirações e objetivos pessoais de cada um. Não há prérequisito ou sequência definida, assim pode ser desenvolvida uma ou várias áreas do planejamento.

\subsection{Planejamento Individual}

O planejamento individual é um processo de profunda reflexão, baseado nos valores, desejos, sonhos e aspirações de cada indivíduo, que permite uma análise de sua vida com a percepção de quais os aspectos deseja mudar, desenvolver, manter ou atingir (FREIRE 2005). Desse modo, o planejamento individual é estritamente pessoal, enfocando aspectos que apenas dizem respeito àquele indivíduo, propondo seu desenvolvimento e equilíbrio por meio de seis campos: Saúde, Economia, Finanças, Afetividade, Lazer/Cultura e Tempo. 


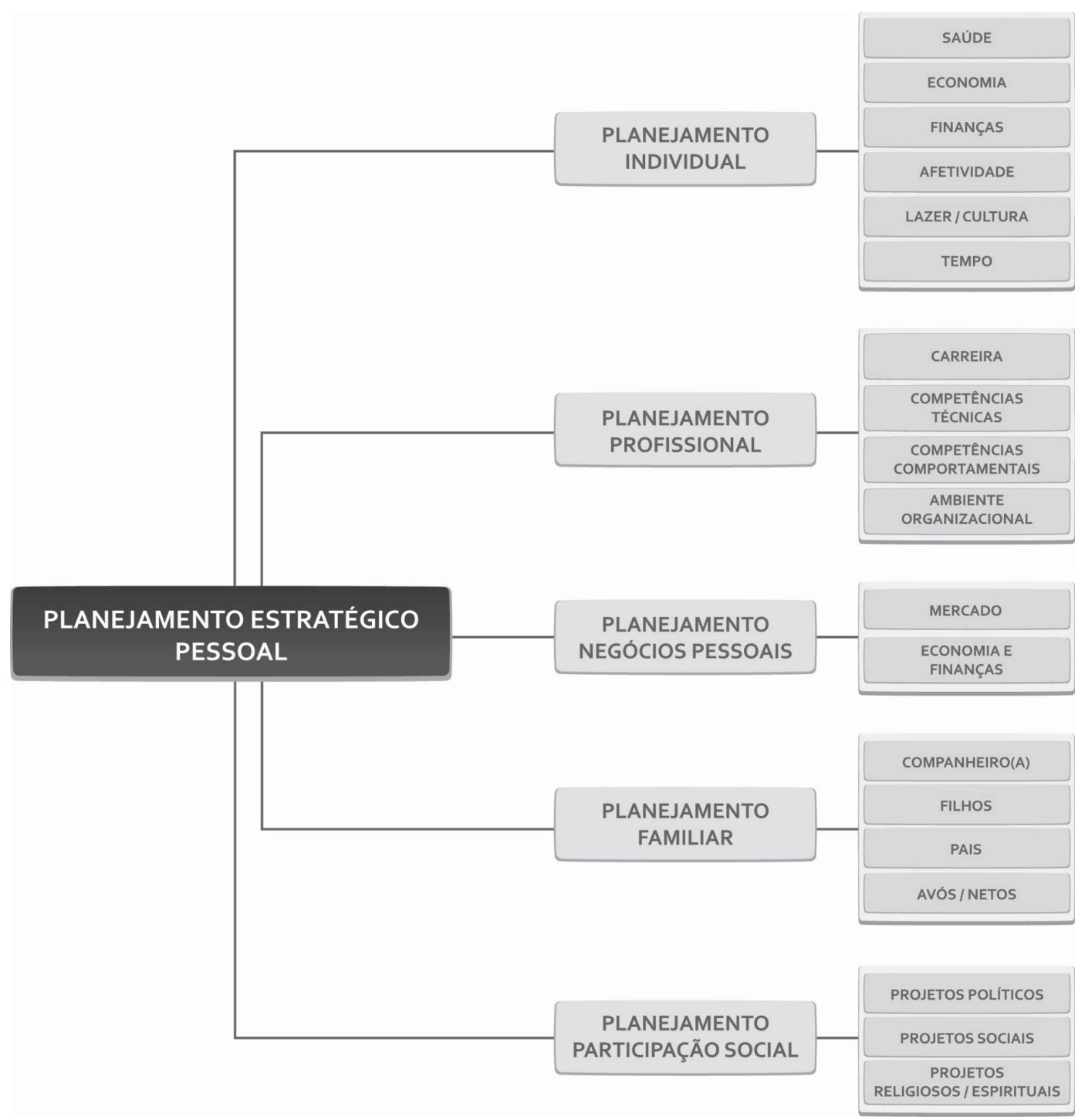

Figura 2: Modelo de Planejamento Estratégico Pessoal proposto Fonte: Elaborada pelos autores

O planejamento da saúde é composto por duas esferas diferentes: a Saúde Mental, diretamente relacionada com as condições de vida impostas pela sociedade atual, e a Saúde Física, que corresponde à boa disposição do corpo, à força e ao vigor. No modelo proposto, enfatiza-se a saúde física, e os elementos a serem considerados são: alimentação, atividade física, controle médico e saúde mental. 
A Afetividade consiste na capacidade de amar, de ser bom, simpático, cordial, altruísta. Ela desempenha um importante papel no desenvolvimento da personalidade humana, pois caracteriza a forma como o ser humano se relaciona com os outros e sua capacidade de estabelecer laços de união (LOURENÇO, 2008). O planejamento do campo afetividade contempla o relacionamento com outras pessoas, a qualidade e a quantidade desses relacionamentos, assim como as comemorações. Segundo Proença (2003), as pessoas se sentem mais feliz quando partilham seus momentos alegres, pois é no bom relacionamento que conseguem estabilidade para desenvolver suas atividades diárias.

Por sua vez, a importância da realização de um planejamento estratégico econômico deve-se ao fato de muitas pessoas não terem a mais vaga ideia de seu patrimônio, e de quanto é necessário para se manterem, de forma confortável, por um mês (LUQUET, 2000). Ao planejar a Economia, é importante que o indivíduo considere o quanto de dinheiro e bens ele possui, e quanto gostaria de ter. Dessa forma, esse campo resume-se ao planejamento dos bens que a pessoa deseja ter no futuro.

Segundo Ferreira (2006), finança pessoal é o processo de planejamento, organização e controle do dinheiro a curto, médio e longo prazos. Assim, o planejamento do campo finanças estabelece uma estratégia para a acumulação de bens e valores que formarão o patrimônio individual. Esse planejamento considera a aplicação, que corresponde ao "[...] emprego de capital para produzir rendimentos [...]" (RIOS, 2006, p. 102), e ao rendimento, que consiste no valor proveniente de aplicações, ou aos investimentos, que geram lucro, ou juros, para a pessoa, sem que seja necessário trabalhar para isso (FERREIRA, 2006).

A Afetividade consiste na capacidade de amar, de ser bom, simpático, cordial, altruísta. Ela desempenha um importante papel no desenvolvimento da personalidade humana, pois caracteriza a forma como o ser humano se relaciona com os outros e sua capacidade de estabelecer laços de união (LOURENÇO, 2008). O planejamento do campo afetividade contemplam o relacionamento com outras pessoas, a qualidade e a quantidade desses relacionamentos, assim como as comemorações. Segundo Proença (2003), as pessoas se sentem mais felizes quando partilham seus momentos alegres, pois é no bom relacionamento que conseguem estabilidade para desenvolver suas atividades diárias. 
O lazer é um conjunto de ocupações destinadas à recreação, ao repouso, à diversão e ao entretenimento que podem envolver a participação social voluntária e o desenvolvimento da capacidade criativa, após liberarse das obrigações profissionais, familiares e sociais (DUMAZEDIER, 1976). Por sua vez, a cultura refere-se a um sistema de atitudes, a um modo de agir, aos costumes e aos valores espirituais e materiais de uma sociedade que influenciam no comportamento do indivíduo, contribuindo para o desenvolvimento do intelecto, do conhecimento, da arte e a da ciência (NERY; VANZIN, 2002).

Assim, para o planejamento desses dois campos, consideram-se as atividades viagens, saídas e hobbys, as quais podem ser desenvolvidas como formas de lazer ou de cultura, visto que esses dois campos estão interligados.

Segundo Proença (2003), embora democraticamente distribuído, o tempo é um recurso altamente perecível, pois aquilo que se deixa de usar no dia de hoje não mais pode ser recuperado. A falta de organização pessoal desperdiça muitas oportunidades, consumindo, em excesso os recursos, direcionando esforços para atividades erradas. É necessário planejar o aproveitamento do tempo, uma vez que a sua correta utilização dá-se na organização básica vivida no dia a dia (PIRES, 2005). Portanto, administrar o tempo de maneira eficaz significa alinhar as atividades, as metas, os sonhos, as obrigações, os sentimentos, os valores e as motivações de forma coerente e dinamizada, tendo em vista o foco no que é mais importante, conhecer as reais prioridades e equilibrar todos os aspectos da vida do indivíduo que está realizando o planejamento.

\subsection{Planejamento Profissional}

Para Hall (2004), a grande vantagem de realizar o planejamento profissional reside em poder equilibrar as aspirações profissionais com os pessoais, uma vez que ficam claros os objetivos e os meios para alcançá-los. Assim, quando uma pessoa desenvolve um plano de carreira, cuidadosamente preparado e alinhado com seu propósito maior de vida, todas as tempestades, crises, mudanças e instabilidades da vida profissional se transformam em novas oportunidades. Para isso, o modelo compreende a análise de quatro campos: a carreira, as competências técnicas, as competências comportamentais e o ambiente organizacional, cujo trabalho integrado con- 
tribui para o desenvolvimento do profissional como um todo, englobando questões técnicas, comportamentais e emocionais (FERNANDES, 2007).

De acordo com Macedo (2004), o profissional tornou-se responsável pelo planejamento e gerenciamento de sua carreira, e, considerando suas experiências pessoais, é possível escolher o caminho mais adequado que o leve a autorrealização. Assim, a carreira pode ser reinventada sempre que necessário para satisfazer as aspirações do indivíduo (HALL, 2004). Para a elaboração do planejamento profissional, divide-se a carreira em três elementos: função, cargo e remuneração.

As competências técnicas contemplam conhecimentos e habilidades do indivíduo, que o auxiliarão no desempenho das funções específicas de um cargo (RABAGLIO, 2001). Segundo Durand (2000), o conhecimento corresponde a uma série de informações que o ser humano assimila e acumula ao longo de sua vida e lhe permite entender o mundo. Para Sveiby (1998) e Rabaglio (2001), a habilidade é a arte de saber fazer. Ela envolve uma prática física e mental e é adquirida, sobretudo, por treinamento, incluindo o conhecimento de regras, de procedimentos e habilidades de comunicação. Os elementos considerados fundamentais, dentro das competências técnicas, são: formação (graduação e pós-graduação); atualização (curta e longa duração); idiomas (entendimento e fluência) e estágios (nacionais $e$ internacionais).

Investir apenas na formação específica e em qualificações técnicas deixou de ser um diferencial, pois, segundo Cabrera (2003, p. 56), "[...] as competências técnicas são essenciais, mas não sobrevivem ao tempo". Em função das novas necessidades do mercado, as atenções têm se voltado às habilidades comportamentais do indivíduo. Fernandes (2007) destaca que as competências comportamentais podem ser inerentes à personalidade do profissional ou podem ser desenvolvidas através de treinamentos e do convívio social.

Elas correspondem ao conjunto de atitudes e comportamentos que proporcionam melhores resultados às atividades desempenhadas nas organizações (RABAGLIO, 2001). O planejamento desse campo considera o autoconhecimento, a emoção, a comunicação, a aprendizagem e a liderança.

Na concepção de Fernandes (2007), o ambiente organizacional corresponde ao meio em que a empresa atua. É um conjunto de fatores internos e externos que exercem algum tipo de influencia sobre a mesma. $\mathrm{O}$ 
ambiente externo refere-se aos concorrentes, clientes, fornecedores, sociedade e todas as forças que afetam, de forma direta e/ou indireta a organização, sobre os quais a empresa não tem controle ou controla, apenas, parcialmente. $\mathrm{O}$ ambiente interno envolve as pessoas que trabalham na organização, local, instalações físicas e equipamentos, e sobre os quais ela possui algum tipo de controle. Para efeito de planejamento profissional, será enfatizado o ambiente interno, considerando as pessoas, o local, as instalações físicas e os equipamentos.

\subsection{Planejamento Familiar}

A família consiste num "[...] grupo de pessoas ligadas entre si pelos vínculos de casamento, parentesco ou afinidade" (CRUZ, 1942, p. 1). O planejamento da área familiar envolve a melhoria e a otimização das relações com companheiro(a), filhos, pais, avôs e netos, abordando, também, em alguns campos, questões como dependência e individualidade. A importância desse planejamento deve-se ao fato de a família ser uma unidade complexa e essencial para o processo de viver de todo ser humano (ALTHOFF, 2001).

Ao realizar o planejamento do campo Companheiro(a), devem ser considerados dois aspectos: a individualidade e o relacionamento. Por companheiro(a) entende-se alguém que esteja partilhando da vida da pessoa, no momento. Nesse modelo, pressupõe-se que o relacionamento, entre os companheiros, seja baseado em amor. Brun (2003) contribui afirmando que é a partir do amor que se constrói um caminho a dois, no qual cada um é uma unidade singular e, juntos, formam um projeto comum.

Entretanto, além da existência de projetos compartilhados, é importante que a individualidade de cada pessoa seja preservada, em uma relação, pois são seus projetos individuais que lhe permitem construir sua vida, seus desafios, suas motivações e seus prazeres. Caso contrário, a pessoa fica condicionada às vontades do companheiro(a), situação que só conduz a uma vivência de autoestima asfixiada e restrita (BRUN, 2003).

Embora a existência de problemas num relacionamento seja inevitável, companheiros emocionalmente inteligentes são capazes de conviver com eles, de evitar situações que possam agravá-los e de desenvolverem estratégias que os ajudem a enfrentá-los (GOTTMAN, 2003). Dessa forma, planejar o relacio- 
namento possibilita que a convivência com o companheiro(a) seja melhorada e aperfeiçoada, contribuindo para aumentar a felicidade do casal.

O campo do planejamento Filhos refere-se à quantidade de filhos desejados, ao relacionamento da pessoa com os seus filhos e à dependência deles. Relativo à quantidade, o casal pode estabelecer e planejar quantos filhos deseja ter. De acordo com Tiba (2007), ao nascerem, os filhos são de total dependência dos pais, pois precisam que lhes deem os cuidados básicos, sem os quais eles não sobrevivem. Essa condição modifica-se à medida que os filhos crescem.

Considerando-se que o relacionamento entre pais e filhos deve ser fundamentado no amor e no diálogo, "[...] aos pais cabem decisões de como educar os filhos e o fazem conforme a construção de seus significados simbólicos e a realidade que vivenciam" (LEITE, 2004, p. 56). Centa (2001) considera que a família, à medida que exerce e põe em prática seu papel, tem fundamental importância na construção dos projetos de vida, dos valores e crenças da criança. No entanto, normalmente, na adolescência, os jovens começam a interiorizar novos valores ao se relacionarem com grupos externos e, em função da diferença de valores aprendidos na sociedade em relação aos valores familiares, os conflitos tendem a ser estabelecidos (LEITE, 2004). A isso se deve a importância do planejamento na área.

O planejamento do campo Pais diz respeito ao relacionamento da pessoa com os seus pais, bem como sua dependência a eles. A relação de dependência, nesse campo, refere-se aos cuidados e aos fatores financeiros. À medida que os filhos crescem, tornam-se capazes de cuidar de si, e a relação de dependência diminui. Esse processo depende do empenho dos filhos e da compreensão dos pais, em que o processo de maturação deve estimular de forma progressiva e simultânea a responsabilidade e a liberdade dos jovens (PY, 2007). No que tange aos relacionamentos, Teixeira, Froes e Zago (2006) alertam para as mudanças na comunicação da família, em função da interferência da modernização, já que muitos problemas familiares devem-se à falta de intimidade de pais e filhos, fato que pode ser solucionado através do diálogo.

Os Avós exercem influência na vida dos netos, tanto no aspecto pessoal como no social e são percebidos pelos netos como pessoas amáveis e importantes. Essa percepção deve-se ao fato de que "[...] as emoções que estão subjetivamente no relacionamento entre avôs e netos são representadas pela paciência, carinho, atenção e afeto que os avôs devotam aos netos" 
(LEITE, 2004, p. 62). Giddens (2000) acrescenta que esse relacionamento baseia-se na compreensão do ponto de vista do outro, sendo, para isso, essencial a interação, a conversa e o diálogo. Contudo, o relacionamento entre avós e netos também apresenta tensões, uma vez que os avós podem reproduzir a autoridade dos pais (LEITE, 2004). Portanto, o planejamento desse campo estimula as pessoas a desenvolverem formas que equilibrem $e$ amenizem essas tensões, otimizando as relações netos/avós e vice-versa, de forma a proporcionar momentos de prazer para ambos.

\subsection{Planejamento de Negócios Pessoais}

O propósito do planejamento de negócios pessoais reside na preparação da pessoa para atuar como empreendedor, ou empresário, no meio organizacional. Sendo assim, essa área divide-se em dois campos: mercado e economia e finanças.

Machado (2003, p. 9) explica que o mercado é

[...] um relacionamento entre empresas e pessoas que querem oferecer produtos e serviços, e empresas ou pessoas que necessitam consumir aqueles produtos ou serviços.

O mercado pode ser analisado em três dimensões: mercado consumidor, mercado concorrente e mercado fornecedor. Segundo Aaker (2001), para se inserir no mercado, as empresas precisam definir os produtos ou serviços que irão oferecer, o mercado ou segmento que desejam servir e com quais competidores deverão competir. Portanto, esse planejamento, visa conhecer e determinar o mercado de atuação, pois a análise de suas características é fundamental para o sucesso de qualquer empreendimento.

O campo da Economia e das Finanças compreende o estudo do patrimônio, da rentabilidade e da lucratividade da empresa. Para Aloe (1973, p. 24) o patrimônio consiste no "[...] conjunto de valores à disposição de uma empresa em dado momento". Esse patrimônio representa uma grandeza complexa, formado pelo conjunto de bens (tudo aquilo que a empresa possui para uso, troca ou consumo), direitos (valores a receber) e obrigações (valores a pagar) que a empresa possui (AUTRAN; COELHO, 2003). A rentabilidade, segundo Autran e Coelho (2003, p. 118), é "[...] o grau de êxito econômico obtido por uma empresa em relação ao capital nela investido". 
De modo geral, uma empresa terá boa rentabilidade quando for capaz de obter lucro com regularidade. Visto que as empresas e seus proprietários têm como objetivo o lucro. A lucratividade, segundo Gitman (1997), é o retorno de capital medido em relação às vendas, ao ativo ou ao patrimônio da empresa, essa mensuração permite visualizar se as atividades da empresa obtiveram lucro ou prejuízo.

\subsection{Planejamento da Participação Social}

O Planejamento da Participação Social divide-se em três campos: planejamento político, social e religioso/espiritual e visa proporcionar crescimento ao indivíduo, através da organização de suas atividades, do desenvolvimento de relações interpessoais e da interiorização de crenças e valores.

Segundo Pereira et al. (1995, p. 56) o Planejamento Político "[...] procura reunir todos os possíveis elementos que vão compor as ações futuras e organizá-los de uma forma articulada". Esse campo visa preparar a pessoa para concorrer, profissionalmente, a cargos políticos e partidários em nível municipal, estadual ou nacional, por meio da elaboração de estratégias eleitorais e da organização da campanha. É importante definir a disposição funcional das pessoas envolvidas na campanha, a fim de determinar as atribuições pertinentes a cada uma. A seguir, o planejamento deve ser operacionalizado através de um cronograma de atividades.

Por sua vez, o desenvolvimento de um Planejamento Social permite que o indivíduo obtenha melhores resultados pessoais e profissionais por meio da participação social. Luks (2003) constata, em seus estudos, que as pessoas que ajudam os outros têm melhor saúde, redução da ansiedade e do estresse. A participação social pode ser manifestada de forma voluntária, em que a pessoa colabora, espontaneamente, em causas sociais e comunitárias, e na mobilização de instituições e grupos organizados, como clubes, empresas, universidades, sindicatos, ONGs, etc. É necessário, então, reconhecer os benefícios de se viver em comunidade e pertencer a um grupo social, de forma a desenvolver atividades compatíveis com as metas pessoais do indivíduo.

O último campo, que compõe o Planejamento da Participação Social, refere-se ao Planejamento religioso/espiritual. Segundo o Dalai Lama (2000), enquanto a religião está relacionada aos ensinamentos ou aos dogmas religiosos, aos rituais e às orações; a espiritualidade refere-se às qualidades 
do espírito humano (tais como amor e compaixão, paciência, tolerância, capacidade de perdoar, contentamento, noção de responsabilidade e noção de harmonia), que trazem felicidade, tanto para si quanto para os outros. Considerando que a fé parece ajudar os indivíduos a lidarem com maior eficácia diante de crises pessoais e acontecimentos traumáticos (DALAI LAMA, 2000), o planejamento desse campo tem por objetivo instigar a reflexão do indivíduo no que tange às suas crenças e valores, de forma a torná-lo mais feliz.

\section{Validação do Modelo}

Para a validação do modelo proposto utilizou-se a técnica de entrevista semiestruturada, para isso, foram entrevistadas nove pessoas cujo perfil foi traçado a partir dos seguintes itens: sexo, idade, estado civil, quantidade de filhos e formação profissional.

Foram entrevistados seis homens e três mulheres. A idade média foi de 38,67 anos, cujas idades eram de: 24, 29, 30, 31, 41, 44, 49 e 50 anos (duas pessoas). Em relação ao estado civil, constatou-se que dois dos entrevistados eram solteiros, cinco casados, um divorciado e um possuía união estável. Quanto à quantidade de filhos, três pessoas possuíam dois filhos, dois possuíam cinco filhos, um entrevistado possuía um filho e três entrevistados não tinham filhos.

Todos os entrevistados estavam trabalhando e nenhum deles trocou de empresa durante o período de planejamento. O profissional que possuía a contratação mais recente tinha um ano e meio de serviço na mesma empresa, enquanto o mais antigo tinha 28 anos de empresa.

Referente à formação, um dos entrevistados possuía segundo grau, dois possuíam ensino superior incompleto: sendo que um estava cursando Arquitetura e Urbanismo, e o outro, Sistemas de Informação. Três entrevistados possuíam ensino superior completo: um graduado em Administração, $e$ dois em Química Industrial. Um entrevistado possuía especialização em Finanças, enquanto outro estava cursando a mesma especialização. Um dos entrevistados estava cursando mestrado, na área de Controladoria, na UFRGS (Universidade Federal do Rio Grande do Sul).

O modelo proposto compreende o planejamento de cinco áreas: Planejamento Individual, Planejamento Profissional, Planejamento Familiar, Planejamento de Negócios Pessoaise Planejamento da 


\section{Participação Política, Social e Religioso/Espiritual e seus respectivos} campos.

Seis, dos nove entrevistados, realizaram seu planejamento pessoal em grupo, em forma de seminário, no qual o profissional responsável pela aplicação do processo expôs a parte teórica para todo grupo e colaboram, individualmente, na elaboração dos planos. Os outros três entrevistados realizaram o planejamento de forma particular, individualmente com o profissional responsável.

Constatou-se que os planejamentos Individual e Profissional foram desenvolvidos pelos nove entrevistados, o Planejamento Familiar foi planejado por oito deles, o planejamento de Negócios Pessoais não foi planejado por nenhum dos nove entrevistados e o planejamento da participação Social foi realizado por cinco pessoas.

Visto que nem todos os campos e os elementos dos respectivos planejamentos foram realizados por todos os entrevistados. A Tabela 1 oferece um panorama que contempla o número de entrevistados que planejou determinada área, bem como os que deixaram de planejá-las.

Tabela 1: Perfil das pessoas que avaliaram o modelo de Planejamento Pessoal

\begin{tabular}{|c|c|c|}
\hline $\begin{array}{c}\text { Áreas, Campos e Elementos do Planejamento } \\
\text { Estratégico Pessoal }\end{array}$ & $\begin{array}{l}\text { Quantidade de pessoas } \\
\text { que planejaram esta área }\end{array}$ & $\begin{array}{l}\text { Quantidade de pessoas } \\
\text { que não planejaram esta } \\
\text { área }\end{array}$ \\
\hline Planejamento Individual & 9 & 0 \\
\hline \multicolumn{3}{|l|}{ Campos: } \\
\hline Afetividade & 5 & 4 \\
\hline Economia & 7 & 2 \\
\hline Finanças & 9 & 0 \\
\hline Saúde & 7 & 2 \\
\hline Lazer/Cultura & 5 & 4 \\
\hline Tempo & 2 & 7 \\
\hline Planejamento Profissional & 9 & 0 \\
\hline \multicolumn{3}{|l|}{ Campos: } \\
\hline Carreira & 4 & 5 \\
\hline Competências Técnicas & 9 & 0 \\
\hline \multicolumn{3}{|l|}{ Elementos } \\
\hline Graduação & 3 & 5 \\
\hline $\begin{array}{l}\text { Pós-graduação lato sensu } \\
\text { (Especialização e MBA) }\end{array}$ & 1 & 7 \\
\hline $\begin{array}{l}\text { Pós-graduação stricto sensu } \\
\text { (Mestrado e Doutorado) }\end{array}$ & 4 & 4 \\
\hline Formação & 8 & 1 \\
\hline Atualização & 5 & 4 \\
\hline Idiomas & 4 & 5 \\
\hline Estágio & 0 & 9 \\
\hline Competências Comportamentais & 3 & 6 \\
\hline Ambiente Organizacional & 0 & 9 \\
\hline
\end{tabular}




\begin{tabular}{l|l|l}
\hline Planejamento Familiar & 8 & 1 \\
\hline Campos: & & \\
\hline Relacionamento com o companheiro(a) & 5 & 3 \\
\hline Relacionamento com os pais & 2 & 6 \\
\hline Relacionamento com os filhos & 6 & 2 \\
\hline Relacionamento com avós ou netos & 0 & 8 \\
\hline & & \\
\hline Planejamento de Negócios Pessoais & 0 & 9 \\
\hline & & \\
\hline Planejamento da Participação Social & 5 & 0 \\
\hline Campo: & & \\
\hline Projetos Políticos & 0 & 5 \\
\hline Projetos Sociais & 5 & 0 \\
\hline Projetos Religiosos/Projetos Espirituais & 3 & 2 \\
\hline
\end{tabular}

\section{Conclusão e Recomendações}

Por meio da fundamentação teórica e da análise de alguns modelos de planejamento pessoal existentes, foi possível desenvolver um Modelo de Planejamento Estratégico Pessoal diferenciado, que contempla as diversas áreas da vida do indivíduo (individual, profissional, familiar, empresarial e social).

Para a validação do Modelo de Planejamento Estratégico Pessoal proposto, sua utilização foi testada com nove pessoas, que se mostraram satisfeitas com os benefícios da elaboração e implementação deste Modelo de Planejamento Estratégico Pessoal. Tais benefícios compreendem uma significante melhora nos relacionamentos familiares, profissionais e sociais; melhora da autoestima; estabelecimento de prioridades e melhor utilização do tempo, como evidenciado pelo relato de alguns dos pesquisados:

"O planejamento profissional me trouxe a possibilidade de mudar de curso. A mudança de curso situou-me melhor em relação ao trabalho".

"[...] no campo afetividade, posso dizer que ela melhorou, e hoje estou dialogando mais com as pessoas e com a minha família. Em relação à economia e finanças, pude projetar e definir o objetivo que eu quero atin$\operatorname{gir}[\ldots] " e$

"[...] pude aliviar algumas despesas para poder aplicar mais na poupança. O gerenciamento da minha renda me permite parar de trabalhar daqui um tempo e usufruir o que construí durante toda a minha vida".

Constatou-se que o desenvolvimento do planejamento permitiu uma profunda reflexão por parte dos entrevistados, determinando questões im- 
portantes tais como: saber onde se quer chegar; que tipo de profissional se pretende ser; e com quem gostaria de trabalhar ou se relacionar.

Destaca-se, ainda, a oportunidade de realizar uma autocrítica capaz de identificar os pontos fortes e os pontos a serem melhorados, o que influenciou uma maior procura por aperfeiçoamento.

$\mathrm{O}$ autoconhecimento proporcionado pelo processo de planejamento pessoal contribui para a melhoria da comunicação pessoal e para a redução das preocupações, uma vez que deixa claro os objetivos a serem buscados e a forma como alcançá-los. Da mesma maneira, permite que a pessoa mantenha-se focada nos objetivos durante a implementação, conservando uma visão de longo prazo, como pode ser observado nos trechos a seguir:

"Colocar no papel o que eu queria, pensar e planejar foram muito importantes. Nesse processo, eu fiz uma reflexão profunda sobre a minha vida, sobre os meus desejos, minhas aspirações. Nessa retrospectiva, pude avaliar e planejar os meus objetivos [...]" e

"[...] para mim, o principal benefício é ter conseguido desenvolver um plano de vida. Consegui, com ele, enxergar a longo prazo, criar alguns caminhos".

Considerando que as áreas e os campos do Planejamento Estratégico apresentados neste modelo não se restringem ao exposto, uma vez que podem ser estudadas sob várias perspectivas, recomenda-se:

a) Aplicar o modelo desenvolvido a um maior número de pessoas.

b) Aprofundar cada uma das cinco áreas que compõem o planejamento estratégico pessoal, bem como os seus campos e elementos, totalizando cinco novos estudos. 


\section{Personal Strategic Planning}

\section{Abstract}

Reconciling personal skills with the demands of a globalized and competitive market has become a pre-requisite for professionals aspiring for success in their careers. The quest for personal fulfillment has encouraged people to search for tools which develop their talents and balance their efforts, in order to achieve a better, happier and healthier life. As an option, planning, which historically was restricted to being an organizational tool, today has also come to be used by individuals who desire personal success. In this way, the objective of this article is to develop a model of Personal Strategic Planning which takes into account the various operation areas and human performance. The proposed model is divided into: Individual Planning, Professional Planning, Family Planning, Personal Business Planning and Political Participation, Social and Religious/Spiritual Planning and their respective fields. In order to analyse and validate the model, exploratory research of a qualitative nature was used through primary and secondary data sources. From the results obtained by the model, it is possible to consider their importance to future research, once the studied areas can be developed in subsequent works.

Key words: Personal Strategic Planning. Personal Planning. Career Planning.

\section{Referências}

AAKER, D. A. Administração estratégica de mercado. Porto Alegre: Bookman, 2001.

ALOE, A. Contabilidade Geral. 6. ed. São Paulo: Atlas, 1973.

ALTHOFF, C. R. Convivendo em família: contribuição para a construção de uma teoria substantiva sobre o ambiente familiar. 2001. $174 \mathrm{f}$. Tese (Doutorado em Filosofia de Enfermagem) - Universidade Federal de Santa Catarina, Florianópolis, 2001.

ANSOFF, H. I. et al. Do planejamento estratégico à administração estratégica. São Paulo: Atlas, 1981.

AUTRAN, M.; COELHO, C. U. F. Básico de contabilidade e finanças. Rio de Janeiro: Senac Nacional, 2003. 
BRONDANI, G. O Planejamento Estratégico nas organizações, 1999. Disponível em: <http://www.cgu.gov.br/sfc/ideias/ideias/planeja.htm>. Acesso em: 8 mai. 2006.

BRUN, G. Casamento feliz é aquele que se assemelha a um longo papo, 2003. Informativo da Associação Gaúcha de Terapia Familiar, ano 5, n. 19, dez. 2003. Disponível em: < http://www.agatef.com.br/admin/content/ jornais/arquivos/042007_dezembro2003.pdf>. Acesso em: 2 mai. 2008. Entrevista concedida a Adriana Zanonatto.

CABRERA, L. C. Q. Trabalho, estudo e diversão: a CareerFair 2003 propõe o surgimento do profissional que se coloca $100 \%$ em tudo o que faz. São Paulo, jul. 2003. Revista Exame Você S/A, São Paulo, n. 61, p. 54-59, jul. 2003. Entrevista concedida a Maria Tereza Gomes.

CENTA, M. L. Do natural ao artificial: a trajetória de um casal infértil. Curitiba: Do autor, 2001.

COSTA, C. Por que escrever um Planejamento Estratégico Pessoal? 2005. Disponível em: <http://www.acontecendoaqui.com.br/at_088.php>. Acesso em: 8 mai. 2006.

COTTERMAN, J. D.; WILBER, J. S. StrategicPlanning for Dumies, 2000. Disponível em: <http://www.altmanweil.com/about/articles/ article.cfm?ArticleID=142> . Acesso em: 27 jul. 2006.

COVEY, S. R. Os 7 Hábitos das Pessoas Altamente Eficazes. 12. ed. São Paulo: Best Seller, 2002.

CYGLER, J. Quem mexeu na minha vida? A fórmula do sucesso e da felicidade, sem estresse. Rio de Janeiro: Elsevier, 2005.

CRUZ, G. B. Direito de família. 2. ed. Coimbra: Coimbra Ed., 1942, v. I, p.1. DALAI LAMA, Tenzin Gyatso, O caminho da tranqüilidade. Traduzido por Maria Luiza Newlands Silveira e Márcia Cláudia Alves. Rio de Janeiro: Sextante, 2000.

DIEHL Antônio; TATIM Denise Carvalho. Pesquisa em ciências sociais aplicadas: métodos e técnicas. São Paulo: Editora Pearson Prentice Hall. 2004.

DINSMORE, P. C. O projeto Você. São Paulo, dez. 2002. Revista Você S/A. São Paulo, n. 54, p. 52-9, dez. 2002. 
DUMAZEDIER, Y. Societé éducative et pouvoir cultural. Paris: Du Senil, 1976.

DURAND, M. Doença ocupacional. São Paulo: Escuta, 2000.

FERNANDES, V. A. O planejamento profissional e o seu alinhamento ao planejamento estratégico organizacional. 2007. 101 f. Dissertação (Mestrado em Administração) - Universidade Federal de Santa Maria, Santa Maria. 2007.

FERREIRA, R. Como planejar, organizar e controlar seu dinheiro: manual de finanças pessoais. São Paulo: IOB Thompson, 2006.

FREIRE, A. Paixão por Empreender: como colocar suas idéias em prática. Rio de Janeiro: Elsevier, 2005.

GENTIL, V. Saúde mental, 2008. Disponível em: <http:// drauziovarella.ig.com.br/entrevistas/saudemental.asp >. Acesso em: 23 abr. 2008.

GIDDENS, A. Família. In: O mundo em descontrole: o que a globalização está fazendo de nós. Rio de Janeiro: Record, 2000.

GIL, A. C. Métodos e Técnicas de Pesquisa Social. 5. ed. São Paulo: Atlas, 1999.

\section{2 .}

. Como elaborar projetos de pesquisa. 4. ed. São Paulo: Atlas,

GITMAN, L. J. Princípios de Administração Financeira. 7. ed. São Paulo: Harbra, 1997.

GOTTMAN, J. Uma entrevista sobre amor, paixão, sexo e casamento, 2003. Informativo da Associação Gaúcha de Terapia Familiar, ano 5, n. 19, dez. 2003. Disponível em: < http://www.agatef.com.br/admin/content/jornais/ arquivos/042007_dezembro2003.pdf > . Acesso em: 2 mai. 2008. Entrevista concedida a Luiz Carlos Prado.

HALL, R. Organizações: estrutura e processos. 3. ed. Rio de Janeiro: Prentice-Hall, 2004.

KOSHY, S. Personal Strategic Planning.Winnipeg: Compass, 2005. 
LEITE, I. L. Gênero, família e representação social da velhice. Londrina: Eduel, 2004.

\section{LOURENÇO, M. S. M. Construindo a afetividade de nossos filhos:} formamos nossas crianças com relacionamentos afetivos positivos, 2008. Disponível em: <http://www.cancaonova.com/portal/canais/formacao/ internas.php\%3Fid\%3D\%26e\%3D9131+ construindo $+\mathrm{a}+$ afetividade + de + nossos + filhos\&hl + pt-BR\&ct $=\mathrm{clnk} \& \mathrm{~cd}=1 \& \mathrm{gl}=\mathrm{br}>$. Publicado em 26 de março de 2008. Acesso em: 23 abr. 2008.

LUKS, A. Voluntários vivem mais e com maior saúde! 2003. Disponível em: <http://www.voluntarios.com.br/brasil.htm>. Acesso em: 9 mai. 2008.

LUQUET, M. Guia Valor Econômico de finanças pessoais. São Paulo: Globo, 2000.

MACEDO, G. B. Planeje sua carreira com inteligência (Parte I). VOCÊ S/A. 2004. Disponível em: <http://vocesa.abril.com.br/aberto/colunistas/ pgart_0701_20042004_38005.shl>. Acesso em: 19 abr. 2007.

MACHADO, J. R. A arte de administrar pequenos negócios. Rio de Janeiro: Qualitymark, 2003.

MORRISEY, G. L. Creating Your Future: personal strategic planning for professionals. San Francisco, CA: Berrett-Koehler Publishers, 1992.

NAVARRO, L. Planejamento Estratégico Pessoal. 2006. Curso Online de Planejamento Estratégico Pessoal. Disponível em: <http:// www.webtraining.com.br/servlet/ServletSigaDesktop?action = showInicio $>$. Acesso em: $1^{\circ}$ set. 2006.

NERY, M. E. S.; VANZIN, A. S. Enfermagem em Saúde Pública. 3. ed. Porto Alegre: RM\&L, 2002.

OLIVEIRA, D. P. R. de. Planejamento estratégico: conceitos, metodologias e práticas. 18. ed. São Paulo: Atlas, 2002.

PEREIRA, H. P. et al. Como agarrar seu eleitor: manual de campanha. São Paulo: Senac, 1995.

PIRES, N. Planejamento Estratégico Pessoal, 2005. Disponível em: <http:/ /www.eap.ap.gov.br/imagens/download/planejamento.ppt>. Acesso em: 28 ago. 2006. 
PORTILlO, J. Strategic Personal Planning. Kansas: TerraceTrailPress, 1997.

PRADO, L. J. Planejamento Estratégico Pessoal para uma vida melhor! 2006. Disponível em: <http://www.cgu.gov.br/sfc/ideias/ideias/ planeja.htm>. Acesso em: 8 mai. 2006.

PY, L. A. Relação de dependência entre pais e filhos. 2007. Disponível em: <http://www.paradigma-sc.com.br/rentacontrol/bv/arquivos/ 2007_05_15_UN15.pdf >. Acesso em: 2 mai. 2008.

PROENÇA, J. Planejamento Pessoal e Administração do Tempo: otimização do tempo com o Pocket PC. São Paulo: IEditora, 2003.

RABAGLIO, M. Seleção por Competências. São Paulo: Educator, 2001.

RIOS, D. R. Minidicionário escolar da língua portuguesa. São Paulo: DCL, 2006.

SAMPAIO, C. H. Planejamento estratégico. Porto Alegre: Sebrae/RS, 2002.

SEIWERT, L. J. Se tiver pressa, ande devagar. São Paulo: Fundamento Educacional, 2004.

SHIBATA, L. H. Planejamento e vida, 2007. Disponível em: <http:/ www.bernhoeft.com/bernharqcom/artconsult/co11_planvida.htm $>$. Acesso em: 8 ago. 2007.

SOUZA, C. Você é do tamanho de seus sonhos: estratégias para concretizar projetos pessoais, empresariais e comunitários. São Paulo: Gente, 2003.

O momento da sua virada: estratégias que definem o sucesso de pessoas e empresas. São Paulo: Gente, 2004.

STONER, J. A. F.; FREEMAN, R. E. Administração. Rio de Janeiro: PrenticeHall, 1995.

SUA SANTIDADE, O Dalai-Lama. A arte da felicidade: um manual para a vida. Traduzido por Waldéa Barcellos. São Paulo: Martins Fontes, 2000.

SVEIBY, K. E. A nova riqueza das organizações. Rio de Janeiro: Campus, 1998. 
TEIXEIRA, A. N. J.; FROES, R. C.; ZAGO, E. C. A comunicação e o relacionamento da família atual em virtude dos novos tempos. In: REC - Revista Eletrônica de Comunicação. UniFacef, n. 1, jan./jun., 2006.

TIBA, I. Quem ama educa! Formando cidadãos éticos. São Paulo: Integrare, 2007. 